\title{
Exergy Analysis: Absorption heat transformer cycle with a combining ejector using Lithium bromide/water as working fluid
}

\author{
A. Pongtornkulpanich ${ }^{1,2}$ S. Thepa ${ }^{1}$ and M. Amornkitbamrung ${ }^{3}$
}

\author{
${ }^{1}$ Division of Energy Technology, School of Energy and Materials, King Mongkut's University of \\ Technology Thonburi, Bangmod, Thungkru, Bangkok, 10140 (Thailand) \\ ${ }^{2}$ School of Renewable Energy Technology, Naresuan University, Phitsanulok, 65000 (Thailand) \\ Phone: +66-5526-1067, fax: +66-5526-1067, e-mail: anannu@maildozy.com \\ ${ }^{3}$ Division of Thermal Technology, School of Energy and Materials, King Mongkut's University of \\ Technology Thonburi, Bangmod, Thungkru, Bangkok, 10140 (Thailand)
}

\begin{abstract}
In order to upgrade the waste heat to higher process temperatures for recuperation, an ejection absorption heat transformer gives more an effective potential for that purpose and higher system performance than a single-stage one. Thermodynamic analysis, both first and second law, is employed to be a tool for consideration of the quantity and quality of energy in both thermal systems. In this paper, an exergy analysis is comparatively performed on two cycles with lithium-bromide/water as the working pair. The numerical results for the cycle obtained here are tabulated. The thermal properties, entropy, and exergy of the working fluids are also calculated to analyze irreversible loss in system components under operating conditions.
\end{abstract}

Key words: Modified cycle, second law efficiency, exergy, lithium bromide water solution, second law thermodynamic analysis

\section{Introduction}

Many industrial processes release very large amount of waste heat at low temperature to the environment, which cause to be global warming [4]. In order to upgrade these low-grade waste heat for energy utilization, absorption heat transformer (AHT) is one of effective system is used with approximately $50 \%$ of the waste heat recovered and reused [11]. With requirement of larger temperature lift of useful heating effect, absorption heat transformer is modified the cycle with improving system performance together with the mainly above objective. These modified cycles, for example, include two-stage absorption heat transformer, double effect absorption heat transformer and ejection absorption heat transformer [9]. The comparative study show that the temperature of recovered heat and the system performance obtained from the ejection absorption heat transformer cycle are lifter and higher than the others. Most of these studies emphasize the consideration of whole system based on the first law method. To optimize the thermal design of the system, it should show how or where irreversibility in a system occurred.
Second law thermodynamic analysis is an effective tool to determine the magnitude of irreversibility occurred which to be direction to improve the performance of thermodynamic system [1]. The aims of this study are to investigate how or where irreversibilities in the ejection absorption heat transformer and determine the magnitude of irreversibility at any components occurred. In addition, simulation of a modified cycle is employed to evaluate the second law efficiency as compared to the conventional cycle and thermal properties, entropy and exergy of working fluids are calculated to second law thermodynamic analysis.

\section{Operation of an ejection-absorption heat transformer}

The system schematic of the single-stage absorption heat transformer combined with an ejector is shown in Fig.1. The system consists of a generator, a condenser, an evaporator, an absorber, a solution heat exchanger, a solution pump, a refrigerant pump and a solution expansion valve. In Fig.1, a heat source such as waste heat from industrial process is supplied at generator to release water vapor from the weak $\mathrm{LiBr} / \mathrm{H}_{2} \mathrm{O}$ solution. This water vapor is condensed at the condenser to be condensed water, which is delivered to the evaporator. There the water is evaporated by employing waste heat from the same heat source as supplied to the generator. The strong $\mathrm{LiBr} / \mathrm{H}_{2} \mathrm{O}$ solution leaving the generator is pumped through the solution heat exchanger. This heated solution as a primary fluid enters the nozzle, of the ejector in which it expands rapidly. In the exit of the nozzle the solution gets very rapid with low pressure and draws the refrigerant vapor from the evaporator as a secondary fluid. The two fluids mix fully in the mixing tube of the ejector. The mixture leaves the diffuser at the absorber pressure, and enters the absorber. The weak $\mathrm{LiBr} / \mathrm{H}_{2} \mathrm{O}$ solution obtaining at the absorber passes through the solution heat exchanger and returns to the generator for completing the cycle. 


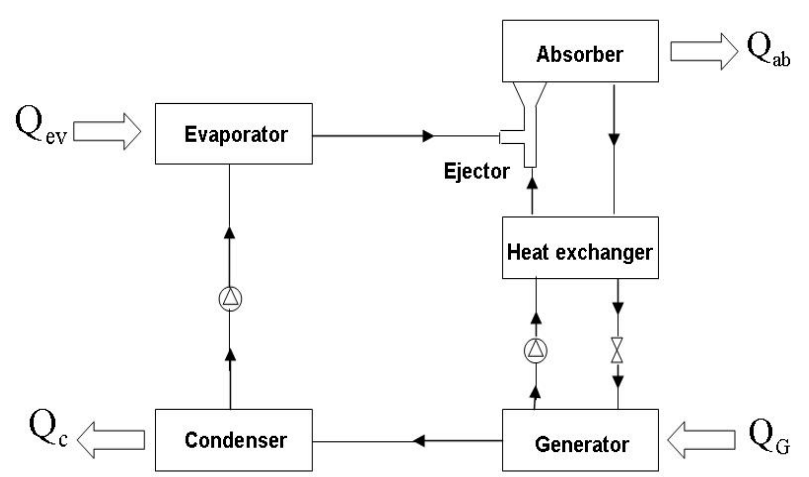

Fig. 1. An ejection-single-stage absorption heat transformer cycle

\section{Second law performance analysis}

\section{Exergy method}

A second law analysis calculates the system performance based on exergy or availability, which always decreases, owing to thermodynamic irreversibility. Exergy is defined as the maximum possible reversible work which can be obtained when the heat rejected from the system is in equilibrium with the surrounding environment. The exergy content of a pure substance is generally given by [1], [10].

$$
\psi=\left(h-h_{O}\right)-T_{O}\left(S-S_{O}\right)
$$

where the terms $h_{o}$ and $S_{o}$ are the enthalpy and entropy of the fluid at the environmental temperature $T_{0}$, which ultimately forms the energy (heat) sinks for all irreversible and reversible processes. However, in a binary mixture solution such as $\mathrm{LiBr}$ and water, the concentration of the mixture must be taken into account for exergy calculation. For a dead state defined as the environmental state at $T_{0}$, the exergy of the solution is calculated by:

$$
\psi=\left(h(X, T)-h_{O}\right)-T_{O}\left(S(X, T)-S_{O}\right)
$$

Steady-flow exergy change or the availability loss in each component can be expressed as

$$
\Delta \psi=\sum m_{i} \psi_{i}-\sum m_{e} \psi_{e}-Q\left(1-\frac{T_{o}}{T}\right)-w
$$

The first term on the right-hand side is the sum of the exergy input. The second is the sum of the exergy output, while the third term is the exergy of heat $Q$, which is transferred at constant temperature $T$. The exergy of heat equals the work obtained by a Carnot engine operating $\mathrm{T}$ and $\mathrm{T}_{\mathrm{o}}$, and is therefore equal to the maximum reversible work that can be obtained from heat energy Q. The last term is the mechanical work transfer to or from the system.

\section{Energy and Exergy Analysis}

The absorption heat transformer cycle has been analyzed thermodynamically as shown in Fig.2. The energy and exergy flow balance for each component of

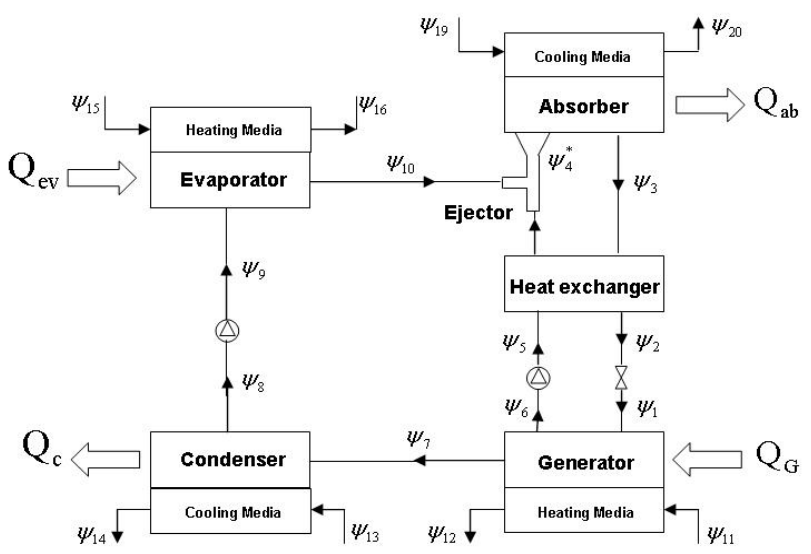

Fig. 2. Exergy flow balance of the absorption heat transformer cycle

the absorption heat transformer cycle can be expressed as follows.

Generator:

$$
Q_{G}=m_{7} h_{7}+m_{6} h_{6}-m_{1} h_{1}
$$

The thermodynamic irreversibility is measured in term of exergy change at any components of the system. The exergy change of the heating media which to be water is obtained from

$$
\Delta \psi_{H M, G}=\dot{m}_{11}\left(\psi_{11}-\psi_{12}\right)
$$

The heat transfer irreversibility is defined as the exergy difference between the exergy of the heat flux and the exergy change of the heating media

$$
\Delta \psi_{h t, G}=Q_{g}\left(1-\frac{T_{o}}{T_{g}}\right)-\Delta \psi_{H M, G}
$$

The internal irreversibility is defined as the exergy difference between the exergy change of the working fluid (solution or refrigerant) and the exergy of the heat flux

$$
\Delta \psi_{\mathrm{int}, G}=\dot{m}_{1} \psi_{S, 1}-\dot{m}_{6} \psi_{S, 6}-\dot{m}_{7} \psi_{R, 7}-Q_{g}\left(1-\frac{T_{o}}{T_{g}}\right)
$$

For the remaining components, the energy and exergy change can be obtained in a similar manner; the equations are given as follows:

Condenser:

$$
Q_{c}=m_{7}\left(h_{7}-h_{8}\right)
$$


Cooling media (CM)

$$
\begin{aligned}
& \Delta \psi_{C M, c}=\dot{m}_{13}\left(\psi_{14}-\psi_{13}\right) \\
& \Delta \psi_{h t, c}=Q_{c}\left(1-\frac{T_{o}}{T_{c}}\right)-\Delta \psi_{C M, c} \\
& \Delta \psi_{\text {int }, c}=\dot{m}_{7}\left(\psi_{R, 7}-\psi_{R, 8}\right)-Q_{c}\left(1-\frac{T_{o}}{T_{c}}\right)
\end{aligned}
$$

Evaporator:

$$
Q_{e v}=m_{9}\left(h_{10}-h_{9}\right)
$$

\section{Heating media (HM)}

$$
\begin{aligned}
& \Delta \psi_{H M, e v}=\dot{m}_{15}\left(\psi_{15}-\psi_{16}\right) \\
& \Delta \psi_{h t, e v}=Q_{e v}\left(1-\frac{T_{o}}{T_{e v}}\right)-\Delta \psi_{H M, e v} \\
& \Delta \psi_{\mathrm{int}, e v}=\dot{m}_{7}\left(\psi_{R, 9}-\psi_{R, 10}\right)-Q_{e v}\left(1-\frac{T_{o}}{T_{e v}}\right)
\end{aligned}
$$

Absorber:

$$
Q_{a b}=m_{10} h_{10}+m_{4} h_{4}-m_{3} h_{3}
$$

\section{Cooling media (CM)}

$$
\begin{gathered}
\Delta \psi_{C M, a b}=\dot{m}_{17}\left(\psi_{18}-\psi_{17}\right) \\
\Delta \psi_{h t, a b}=Q_{a b}\left(1-\frac{T_{o}}{T_{a b}}\right)-\Delta \psi_{C M, a b} \\
\Delta \psi_{\text {int }, a b}=\dot{m}_{7} \psi_{R, 10}+\dot{m}_{6} \psi_{S, 4}-\dot{m}_{1} \psi_{S, 3}-Q_{a b}\left(1-\frac{T_{o}}{T_{a b}}\right)
\end{gathered}
$$

In case of combining an ejector, term of $h_{4}$ of the equation (16) is substituted with term of the enthalpy of solution leaving from ejector to absorber $\left(h_{4}^{*}\right)$. Also, any terms, $\left(\psi_{18}-\psi_{17}\right), Q_{a b}, T_{a b}$ and $\psi_{S, 4}$ in equation (17), (18) and (19), respectively are substituted in terms of $\left(\psi_{20}-\psi_{19}\right), Q_{a b}^{*}, T_{a b}^{*}$ and $\psi_{S, 4}^{*}$ respectively.

Solution heat exchanger (SHE):

$\Delta \psi_{\text {she }}=\dot{m}_{1} \psi_{S, 3}+\dot{m}_{6} \psi_{S, 5}-\dot{m}_{1} \psi_{S, 2}-\dot{m}_{6} \psi_{S, 4}$

Solution pump $(S P)$ :

$$
\Delta \psi_{S P}=\frac{\dot{m}_{6}\left(P_{6}-P_{5}\right)}{\rho_{6}}
$$

\section{Refrigerant pump $(R P)$ :}

$$
\Delta \psi_{R P}=\dot{m}_{7}\left(P_{8}-P_{9}\right) v_{f, 8}
$$

Solution Throttling valve (STV):

$$
\Delta \psi_{S T V}=\frac{\dot{m}_{1}\left(P_{2}-P_{1}\right)}{\rho_{2}}
$$

The total of exergy loss of the absorption heat transformer is the sum of the exergy loss in each component, therefore:

$$
\begin{aligned}
& \Delta \psi_{T}=\Delta \psi_{G}+\Delta \psi_{c}+\Delta \psi_{e v}+\Delta \psi_{a b}+\Delta \psi_{S H E} \\
& +\Delta \psi_{S P}+\Delta \psi_{R P}+\Delta \psi_{S T V}
\end{aligned}
$$

For a combined cycle, the total exergy loss is calculated with equation (24) the same, it differs only the term of exergy loss at the absorber $\left(\Delta \psi_{a b}\right)$ which is replaced with the term of $\Delta \psi_{a b}^{*}$ that the ejector is considered.

\section{Ejector analysis}

In this study, an ejector, which is the key component, is integrated at absorber of an absorption heat transformer to be combined cycle. An ejector employed in this way into the absorption heat transformer cycle increases absorber pressure which equals the exit diffuser pressure of ejector. Also, the combined cycle is called as the three-pressure cycle and this pressure is a major parameter for improving the system performance. The analysis of ejection-absorption heat transformer is the same as single stage heat transformer [9]. The only difference is in the ejector-absorber unit. The ejector mainly consists of a nozzle, a mixing tube and a diffuser.

Nozzle flow

The exit velocity from the nozzle is calculated from

$$
v_{11}^{2}=\frac{E_{N} 2\left(P_{H}-P_{L}\right)}{\rho_{w}}
$$

The mass flow rate is

$$
\dot{m}_{w}=\rho_{w} V_{11} A_{e n}
$$

where $E_{N}$ is the nozzle efficiency, $A_{e n}$ is the nozzle exit area and $\rho_{w}$ is the density of the working fluid.

Flow in the mixing tube

The mixture mass flow rate is

$$
\dot{m}_{\text {mix }}=\dot{m}_{w}+\dot{m}_{R}
$$

And the mixture velocity is

$$
\dot{m}_{w}+\dot{m}_{R}=\rho_{M} A_{M} V_{M}
$$

where $A_{M}=$ cross-sectional area of the mixing tube

$$
\begin{aligned}
V_{M} & =\text { mixture velocity and } \\
\rho_{M} & =\text { mixture density }
\end{aligned}
$$

A momentum balance over the mixing tube yields

$$
\dot{m}_{w} V_{11}+P_{11} A_{M}=\dot{m}_{m i x} V_{M}+P_{M} A_{M}
$$

where $P_{11}$ is the exit nozzle pressure of $\mathrm{LiBr} / \mathrm{H}_{2} \mathrm{O}$ solution 


\section{Diffuser flow}

The mass flow rate in the diffuser, $\dot{m}_{D}$ is

$$
\dot{m}_{D}=\dot{m}_{m i x}=\dot{m}_{w}+\dot{m}_{R}
$$

The energy equation is

$$
E_{D}\left(\frac{V_{M}^{2}-V_{D}^{2}}{2}\right)=\frac{1}{\rho_{D}}\left(P_{E D}-P_{M}\right)
$$

where $E_{D}$ is the diffuser efficiency and $P_{E D}$ is the exit diffuser pressure which equals the absorber pressure $\left(P_{a b}\right)$.

Due to thermodynamic properties correlations of aqueous $\mathrm{LiBr} / \mathrm{H}_{2} \mathrm{O}$ solution given by [2], the following parameters are determined respectively. The refrigerant temperature of aqueous $\mathrm{LiBr} / \mathrm{H}_{2} \mathrm{O}$ solution leaving from ejector at the diffuser, which enters the absorber is determined from the absorber pressure as

$$
R T\left({ }^{o} K\right)=\frac{-2 E}{D+\left[D^{2}-4 E\left(C-\log P_{a b}\right)\right]^{0.5}}
$$

where $C=7.05, D=-1596.49$ and $E=-104095.5$ and $P_{a b}$ in $\mathrm{kPa}$.

Obtained the above refrigerant temperature $(R T)$, the solution temperature $(S T)$ can be determined according to the expression as

$$
S T\left({ }^{o} C\right)=\sum_{n=0}^{3} B_{n} X^{n}+R T\left({ }^{o} C\right) \sum_{n=0}^{3} A_{n} X^{n}
$$

where $A_{o}=-2.00755, A_{1}=0.16976, A_{2}=-3.1333 \mathrm{E}-03$

$$
\begin{aligned}
A_{3} & =1.97668 \mathrm{E}-05, B_{o}=124.937, B_{1}=-7.71649 \\
B_{2} & =0.152286, B_{3}=-7.95090 \mathrm{E}-04 \\
R T & =\text { Refrigerant temperature }\left(-15<R T\left({ }^{o} C\right)<110\right) \\
X & =\text { percent } \operatorname{LiBr}(45<X<70 \%)
\end{aligned}
$$

The enthalpy of solution entering to the absorber $\left(h_{4}^{*}\right)$ can be determined from $\mathrm{LiBr}$ mass fraction and the solution temperature obtained from the above equation. In order to obtain the heat rejected at the absorber in case of combining an ejector $\left(Q_{a b}^{*}\right)$, the energy balance at the absorber according to equation (16) is considered by instead of the enthalpy of solution entering to the absorber $\left(h_{4}\right)$ with the term of $h_{4}^{*}$ which can be written as

$$
Q_{a b}^{*}=m_{10} h_{10}+m_{4} h_{4}^{*}-m_{3} h_{3}
$$

\section{Fluid properties}

In order to calculate the exergy of the lithium bromide/water solution and to conduct the second law analysis, the enthalpy and entropy need to be calculated first. As compared to the enthalpy equation of [7] that of [6] used by [4] gives less fitting extension which leads to larger the standard deviation. Then, the enthalpy equation of the solution employed in this study is based on [7]. The enthalpy of the lithium bromide/water solution is calculated as

$$
h(X, T)=\sum_{i=0}^{K} \sum_{j=0}^{2} A_{i j} X^{i} T^{j}
$$

where $\mathrm{T}=$ Solution temperature $\left(0<T<180^{\circ} \mathrm{C}\right)$ $\mathrm{X}=$ percent $\mathrm{LiBr}(0<X<70 \%)$

The constants appeared in Equation (35) are listed in Table 1. The procedure to calculate the entropy and exergy of the $\mathrm{LiBr} / \mathrm{H}_{2} \mathrm{O}$ solution is obtained from the method proposed by [1] and is summarized below.

The entropy of the $\mathrm{LiBr} / \mathrm{H}_{2} \mathrm{O}$ solution is derived from

$$
\begin{aligned}
& S_{T, X}-S_{T_{\text {ref }}, X_{\text {ref }}}=\int_{T_{\text {ref }}}^{T} \frac{1}{T}\left(\frac{\partial h}{\partial T}\right)_{P, X} d T-\int_{P_{\text {ref }}}^{P}\left(\frac{\partial v}{\partial T}\right)_{P, X} d P \\
& +R\left\{\int_{X_{\text {ref }}}^{X} \frac{\ln a_{\text {water }}-\ln a_{L i B r}}{M_{\text {Sol }}} d X\right\}
\end{aligned}
$$

The first term on the left-hand side in Equation (36) is the entropy of the solution at a specified temperature and concentration. The second term is the reference entropy at a reference state. Here the reference is selected to correspond to $25^{\circ} \mathrm{C}$. Based on the assumptions made by [1], only the temperature variation is considered; thus, the reference entropy is a function of the concentration. The pressure effect on entropy for a liquid may be neglected, and, therefore, the second integral term is canceled out. The last term on the right-hand side is recognized as the difference between the entropy of mixing $\left(\Delta S_{\text {mix }}\right)$ at the reference temperature $T_{r e f}$ and at the temperature $T$. The entropy change as a function of temperature at constant concentration can be expressed as

$$
S_{T}-S_{T_{r e f}}=\int_{T_{r e f}}^{T} \frac{1}{T}\left(\frac{\partial h}{\partial T}\right)_{P, X} d T+\left(\Delta S_{T}-\Delta S_{T_{r e f}}\right)_{m i x}
$$

The integral term can be solved numerically using Equation (38) as follows:

$$
\left(\frac{\partial h}{\partial T}\right)_{P, X} \frac{d T}{T} \approx \frac{h(X, T+d T)-h(X, T)}{T_{D T}(X, T+d T)-T_{D T}(X, T)} \frac{d T}{T}
$$

The dew point temperature correlation employed in this study is described in [7], which is a function of the solution temperature and concentration. The correlation is expressed as

$$
T_{D T}(X, T)=\sum_{i=0}^{K} \sum_{j=0}^{2} B_{i j} X^{i} T^{j}
$$

The constants appeared in Equation (39) are listed in Table 1. And

$$
\Delta S_{\text {mix }}=\frac{-R}{M_{\text {Sol }}}\left[\bar{X}_{L i B r} \log _{e}\left(\bar{X}_{L i B r} \gamma\right)+\bar{X}_{\text {water }} \log _{e}\left(P / P^{*}\right)\right]
$$


where $\quad R=$ universal gas constant $=8.314 \mathrm{~kJ} / \mathrm{kmol} . \mathrm{K}$

$M_{\text {Sol }}=$ Solution molecular weight, which is expressed as

$$
M_{\text {Sol }}=\frac{18.015}{1-0.7926 X}
$$

$\bar{X}=$ mole fractions of $\mathrm{LiBr}$ and water

$\gamma=$ mean molar ionic activity coefficient

$P$ and $P^{*}=$ pressure of water vapor of the solution and pure water

The vapor pressure of the water arising from the $\mathrm{LiBr} / \mathrm{H}_{2} \mathrm{O}$ solution can be calculated from the dew point temperature, which is given by [6]

$$
\log _{10} P=k_{o}+\frac{k_{1}}{T}+\frac{k_{2}}{T^{2}}
$$

where $P=$ partial pressure ( psia $)$

$$
\begin{aligned}
& T=\text { water vapor temperature }\left({ }^{o} R={ }^{o} F+459.7\right) \\
& k_{o}=6.21147 \\
& k_{1}=-2886.373 \\
& k_{2}=-337269.46
\end{aligned}
$$

The reference entropy of the lithium bromide/water solution at $25^{\mathrm{O}} \mathrm{C}$ is

$$
S_{T_{r e f}}=\frac{h_{s o l}-g_{s o l}}{T_{r e f}}
$$

The Gibbs' free energy of the $\mathrm{LiBr} / \mathrm{H}_{2} \mathrm{O}$ solution, $g_{\text {sol }}$ is calculated from

$$
g_{\text {sol }}=\frac{1-X}{M_{L i B r}} \mu_{L i B r}+\frac{X}{M_{\text {water }}} \mu_{\text {water }}
$$

where $X$ is the solution concentration, $M$ is the molecular weight, and $\mu$ is the chemical potential. The chemical potential of water in the solution is

$$
\mu_{\text {water }}=\left(\bar{h}_{v}-T_{\text {ref }} \bar{S}_{v}\right)_{\text {water }}
$$

The enthalpy and entropy of the water vapor are obtained from steam tables at the reference temperature, and the chemical potential of $\mathrm{LiBr}$ in the solution is

$$
\mu_{L i B r}=2 R T_{r e f} \ln (m \gamma)_{L i B r}+\bar{K} T_{r e f}+\mu_{L i B r}^{*}
$$

where $\bar{K}=-192.2 \mathrm{~kJ} / \mathrm{kmol} \mathrm{K}, \gamma$ is the mean molar ionic activity coefficient, and $m_{L i b r}$ is the LiBr molality.

$$
m_{L i B r}=\frac{X}{86.845(1-X)}
$$

The chemical potential of pure $\mathrm{LiBr}$ is

$$
\mu_{L i B r}^{*}=\bar{h}_{L i B r}-T_{r e f} \bar{S}_{L i B r}
$$

This chemical potential becomes zero as pure $\mathrm{LiBr}$ at $25^{\circ} \mathrm{C}$ has been assigned a zero enthalpy and a zero entropy. Then the entropy of the $\mathrm{LiBr} / \mathrm{H}_{2} \mathrm{O}$ solution at $25^{\circ} \mathrm{C}$ can be calculated using Equation (43) through (48). The mean molar ionic activity coefficient, $\gamma$ in Equation (40) and (46) is now calculated as follows. For a single electrolyte solution at $25^{\circ} \mathrm{C}$,

$$
\Gamma^{o}=\left[1+B\left(1+\frac{I}{10}\right)^{q}-B\right] \Gamma^{*}
$$

where $\Gamma^{o}$ is the reduced activity coefficient of pure solution at $25^{\circ} \mathrm{C} ; \quad B=0.75-0.065 q ; q$ is Meissner's parameter $(q=7.27)$

$$
\begin{aligned}
& \log _{e} \Gamma^{*}=(-0.5107 \sqrt{I}) /(1+C \sqrt{I}) \\
& C=1+0.055 q \exp \left(-(0.023 I)^{3}\right)
\end{aligned}
$$

where $I$ is the ionic strength $\left(I=\frac{1}{2} \sum m_{i} Z_{i}^{2}=m_{L i B r}\right) ; Z$ is the number of charges on the cation or anion $(Z=1$ for $\mathrm{LiBr} / \mathrm{H}_{2} \mathrm{O}$ solution). Then the mean molar ionic activity coefficient of the $\mathrm{LiBr} / \mathrm{H}_{2} \mathrm{O}$ solution is calculated from the following relationship:

$$
\gamma=\left(\Gamma^{o}\right)^{Z_{+} Z_{-}}=\Gamma^{o}
$$

With the entropy $S_{T}$ in Equation (37) and the enthalpy calculation, the exergy of the $\mathrm{LiBr} / \mathrm{H}_{2} \mathrm{O}$ solution in Equation (2) can be calculated.

For refrigerant loop, saturated and superheated properties of water and steam employed in this study describes in [4] which approximate equations are developed from steam data tables by Irvine and Liley 1984. These property equations, including the relationships of temperature, pressure, enthalpy, and entropy of water and water vapor are replaced in the corresponding equation.

Saturation temperature $T(S)$

$$
T(S)=A+\frac{B}{\left(\log _{e} P(S)\right)+C}
$$

where $\quad 0.000611 \leq P(S)<12.33 \quad \mathrm{MPa} \quad$ and $273.16 \leq T(S)<600 \mathrm{~K}$

The constant $A, B$ and $C$ in Equation (53) are listed in Table 1.

Saturation pressure $P(S)$

$$
\log _{e} P(S)=\sum_{N=0}^{9} A(N) T(S)^{N}+\frac{A(10)}{T(S)-A(11)}
$$

For calculation of enthalpy and entropy of saturated water and vapor, the following equations need to be calculated first. Then the calculated numbers are substituted into the individual equation of those saturation properties. The constants in Equation (55) for each saturation property are listed in Table 1.

$$
Y(S)=A+B T(C)^{1 / 3}+C T(C)^{5 / 6}+D T(C)^{7 / 8}+\sum_{N=1}^{7} E(N) T(C)^{N}
$$




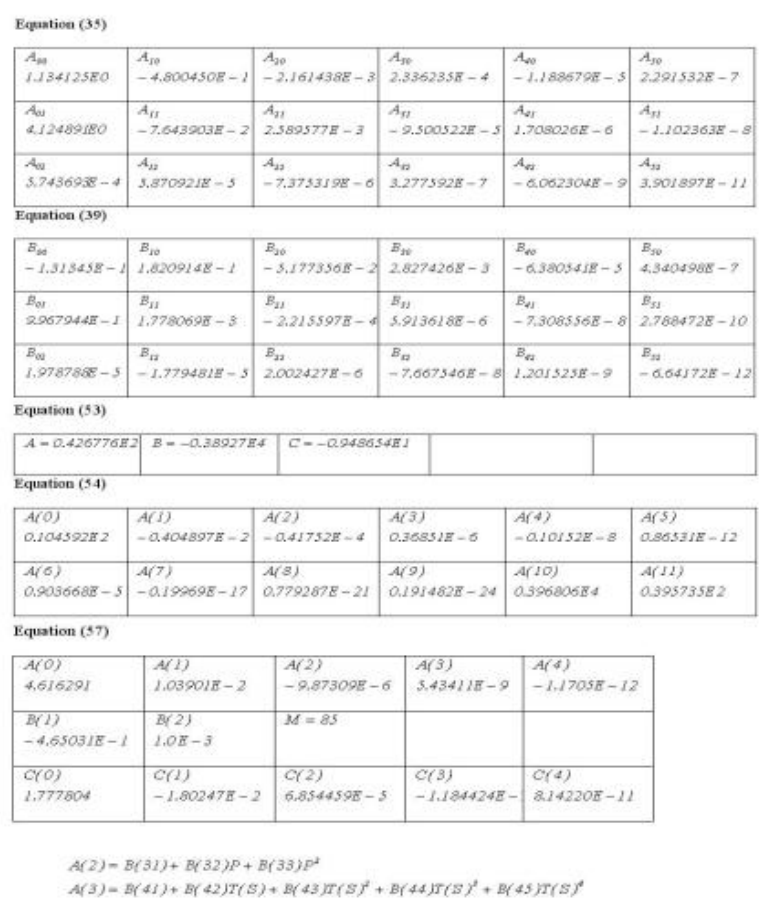

where

$$
\begin{aligned}
& T(C)=[T(C R)-T(S)] / T(C R) \\
& T(C R)=647.3 K
\end{aligned}
$$

Liquid saturation enthalpy:

$$
H(F)=Y(S) H(F C R)
$$

Vapor saturation enthalpy:

$$
H(G)=Y(S) H(G C R)
$$

Liquid saturation entropy:

$$
S(F)=Y(S) S(F C R)
$$

Vapor saturation entropy:

$$
S(G)=Y(S) S(G C R)
$$

The thermodynamic properties equations for superheated water vapor are calculated as functions of pressure $P$ and temperature $T$ as follows.

\section{Enthalpy $H(P T)$}

$$
H(P T)=\sum_{N=0}^{2} A(N) T^{N}-A(3) E X P\left(\frac{T(S)-T}{M}\right)
$$

where

$$
\begin{aligned}
A(0)= & B(11)+B(12) P+B(13) P^{2} \\
A(1)= & B(21)+B(22) P+B(23) P^{2} \\
A(2)= & B(31)+B(32) P+B(33) P^{2} \\
A(3)= & B(41)+B(42) T(S)+B(43) T(S)^{2}+ \\
& B(44) T(S)^{3}+B(45) T(S)^{4}
\end{aligned}
$$

Entropy $S(P T)$

$$
\begin{aligned}
S(P T)= & \sum_{N=0}^{4} A(N) T^{N}+B(1) \ln (10 P+B(2))- \\
& \sum_{N=0}^{4} C(N) T(S)^{N}\left[E X P\left(\frac{T(S)-T}{M}\right)\right]
\end{aligned}
$$

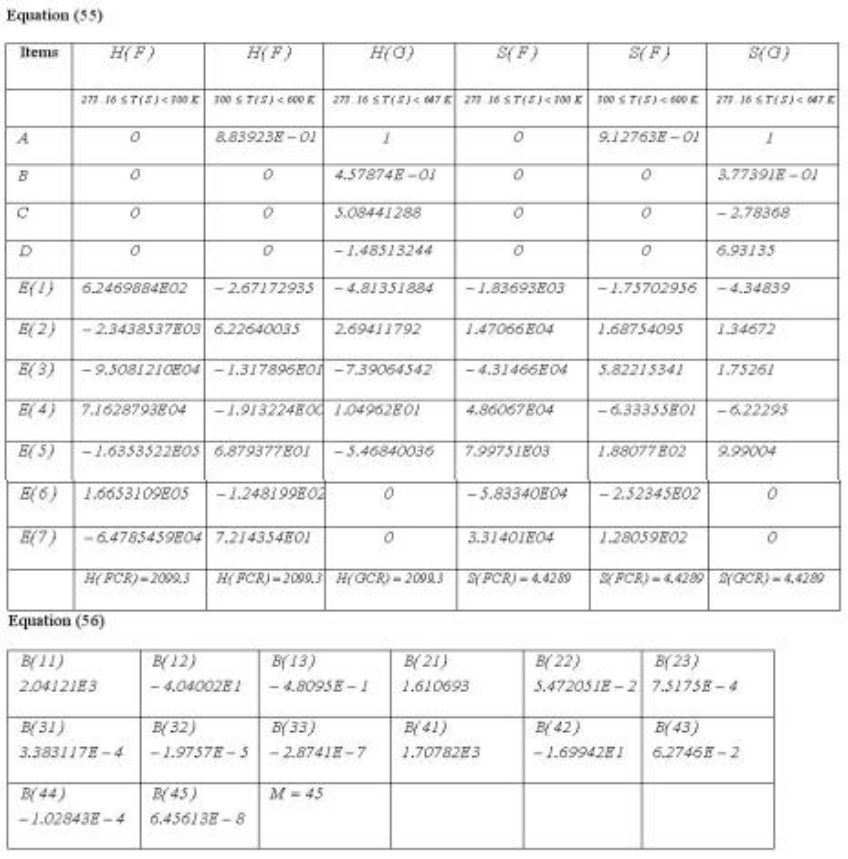

All constants and coefficients for the thermal properties of water and steam in Equations 53 to 57 are listed in Table 1.

\section{The computer program and assumptions}

The $\mathrm{LiBr} / \mathrm{H}_{2} \mathrm{O}$ absorption heat transformer cycle is analyzed and compared thermodynamically both with and without a combining ejector. The computer program is written based on heat and mass balances, heat transfer equations, the mathematical equations of ejector model and thermodynamic properties equations of solution and refrigerant. Here the computer codes are designed to analyze both first law and second law analysis. First law analysis of the system leads to computing a coefficient of performance $(C O P)$, which is defined as the ratio of the upgraded heat obtained from the absorber to the waste heat added to the generator and evaporator. Therefore, the COP equation can be expressed as

$$
C O P=\frac{Q_{a b}}{Q_{e v}+Q_{g}}
$$

and the exergy efficiency is based on the second law is defined as

$$
\eta_{e x}=\frac{Q_{a b}\left(1-\frac{T_{o}}{T_{a b}}\right)}{Q_{g}\left(1-\frac{T_{o}}{T_{g}}\right)+Q_{e v}\left(1-\frac{T_{o}}{T_{e v}}\right)}
$$

In order to analyze the irreversible losses of the system, many subroutines for thermal properties of the working pair are added into the computer code developed by the author to calculate the entropy and exergy of working fluid at each state point, including exergy loss for each of the components and total exergy loss occurred in the system. 
The assumptions of the absorption heat transformer cycle required for input in the computer code are listed in Table 2.

TABLE 2 - Ope rating parameters for the absorption heat transformer cycle

\begin{tabular}{|c|c|}
\hline Various parameters & Value \\
\hline 1. High pressure side, $P_{H}(\mathrm{kPa})$ & 104.1 \\
\hline 2. Low pressure side, $P_{2}(\mathrm{kPa})$ & 16.1 \\
\hline 3. LiBr mass fraction of strong solution, $X_{\text {Las noms }}$ (\%by wt) & 59.4 \\
\hline 4. LiBr mass fraction of weak solution, $X_{\text {List wak }}$ (\%by wt) & 64.0 \\
\hline 5. Mass flow rate of strong solution, $\dot{m}_{3}(\mathrm{~kg} / \mathrm{s})$ & 1.078 \\
\hline 6. Mass flow rate of weak solution, $\dot{m}_{\nu}(\mathrm{kg} / \mathrm{s})$ & 1.000 \\
\hline 7. Mass flow rate of heating/cooling media $\left(\mathrm{H}_{2} \mathrm{O}\right),(\mathrm{kg} / \mathrm{s})$ & 3.000 \\
\hline 8. Effectiveness of solution heat exchanger, , & 0.80 \\
\hline 9. Water temperature: Reference state temperature, $\left.{ }^{\circ} \mathrm{C}\right)$ & 25 \\
\hline 10. Waste heat source temperature, ${ }^{\circ} \mathrm{C}$ & 120 \\
\hline 11. Absorber/Condenser temperature, ${ }^{\circ} \mathrm{C}$ & 30 \\
\hline \multicolumn{2}{|l|}{ Ejector dimension: } \\
\hline 1. Exit nozzle diameter, $D_{n}(\mathrm{~m})$ & 0.0134 \\
\hline 2. Mixing tube diameter, $D_{m}(\mathrm{~m})$ & 0.022 \\
\hline 3. Exit diffuser diameter, $D_{d}(\mathrm{~m})$ & 0.032 \\
\hline 4. Nozzle efficiency, $\eta_{N}$ & $\begin{array}{l}0.90 \\
0.90\end{array}$ \\
\hline 5. Diffuser efficiency, $\eta_{D}$ & \\
\hline
\end{tabular}

\section{Results and discussion}

A theoretical comparative study of thermodynamic between a lithium-bromide ejection absorption heat transformer and a conventional cycle is investigated and presented in this paper. Based on the thermodynamic equation $(P, T, X)$ and $(h, T, X)$, the required enthalpies for each component are obtained for calculations of heat applied at evaporator, heat supplied at generator, heat delivered to condenser and to absorber on both two cycles. With the only different analysis at the ejector-absorber unit, as shown in Figure 1 , the exit diffuser pressure of solution, which is the most significant parameter and equals the absorber pressure $\left(P_{a b}\right)$, is lifted. This pressure causes the solution temperature of inlet solution to the absorber to increase which leads to increased enthalpy of solution entering to the absorber. The energy balance (first law analysis) at the absorber shows that the upgraded heat load is obtained to be increased. Then, the COP of a modified cycle is improved with the value of 0.654 from that of 0.486 for a conventional cycle as compared to the same energy input supplied to the system. Based on energy flow analysis, the sum of the heat input at the evaporator and at the generator is found to be slightly different to that of the heat rejected at the condenser and at the absorber with the energy loss of $0.0669 \mathrm{~kW}$ for a conventional cycle. For a modified cycle, increasing the upgraded heat load at the absorber from the value of $181.081 \mathrm{~kW}$ (for a conventional cycle) to that of $243.770 \mathrm{~kW}$ leads to larger overall energy loss, which equals $62.756 \mathrm{~kW}$.

TABLE - 3 Operating conditions f $\alpha$ the cycle whineat exchangers

\begin{tabular}{|c|c|c|c|c|c|c|}
\hline $\begin{array}{c}\text { State point } \\
\text { (i) }\end{array}$ & $\begin{array}{l}T(f) \\
\left.f^{\circ} \mathrm{C}\right)\end{array}$ & $\begin{array}{c}h(i) \\
(\mathrm{kJ} / \mathrm{kg})\end{array}$ & $\begin{array}{c}s(1) \\
(\mathrm{kJ} / \mathrm{kg} \cdot \mathrm{K})\end{array}$ & $\begin{array}{c}m(t) \\
(\mathrm{kg} / \mathrm{s})\end{array}$ & $\begin{array}{l}X(t) \\
(\% \mathrm{LiBr})\end{array}$ & $\begin{array}{c}\psi(i) \\
(\mathrm{kJ} / \mathrm{kg})\end{array}$ \\
\hline 1 & 96.0 & 281.83 & 0.421 & 1.078 & 59.4 & 160.795 \\
\hline 2 & 125.0 & 281.83 & 0.424 & 1.078 & 59.4 & 160.119 \\
\hline 3 & 153.0 & 332.8 & 0.425 & 1.078 & 59.4 & 210.572 \\
\hline 4 & 144.2 & 325.0 & 0.508 & 1.0 & 64.0 & 177.953 \\
\hline $4^{*}$ & 176.73 & 387.69 & 0.510 & 1.0 & 64.0 & 240.143 \\
\hline 5 & 109.0 & 270.05 & 0.506 & 1.0 & 64.0 & 123.694 \\
\hline 6 & 109.0 & 270.0 & 0.506 & 1.0 & 64.0 & 123.642 \\
\hline 7 & 100.5 & 2688.3 & 10.056 & 0.078 & - & $-305,226$ \\
\hline 8 & 55.40 & 231.94 & 0.7742 & 0.078 & . & 5.7383 \\
\hline 9 & 55.43 & 232.03 & 1.3177 & 0.078 & - & -156.205 \\
\hline 10 & 135.0 & 2754.35 & 2.7540 & 0.078 & . & 1937.88 \\
\hline 11 & 120 & 503.7 & 1.527 & 3.0 & . & 53.046 \\
\hline 12 & 105.96 & 444.24 & 1.389 & 3.0 & . & 34.765 \\
\hline 13 & 30 & 125.7 & 0.438 & 3.0 & . & 0.2686 \\
\hline 14 & 45.29 & 189.85 & 0.641 & 3.0 & . & 3.3072 \\
\hline 15 & 120 & 503.7 & 1.527 & 3.0 & - & 53.046 \\
\hline 16 & 104.29 & 437.21 & 1.371 & 3.0 & . & -404.257 \\
\hline 17 & 30 & 125.7 & 0.438 & 3.0 & - & -0.2686 \\
\hline 18 & 44.46 & 186.32 & 0.631 & 3.0 & . & 2.8326 \\
\hline $19^{4}$ & 30 & 125.7 & 0.438 & 3.0 & . & 0.2686 \\
\hline $20^{*}$ & 49.46 & 207.34 & 0.699 & 3.0 & - & 3.4151 \\
\hline
\end{tabular}

As listed in Table 3, in states 13, 17 and 19, the exergy flow from the water environment is evaluated to be zero because the temperature of the considered system is equal to the environment temperature. Table 4 shows the magnitude of irreversibility in the system components due to the second law detection. It is clear that the absorber has the highest availability loss due to the temperature difference between the absorber and the surroundings. For comparison between both cycles, the larger availability loss at the absorber is obtained in case of a modified cycle due to the higher the temperature difference. This is because the exit diffuser pressure of solution which equals the absorber pressure is lifted with an ejector. This pressure causes the inlet solution temperature to the absorber to increase which leads to increase the enthalpy and entropy of solution. This result can be considered as Table 3 . This entropy of solution increased leads to increasing internal irreversibility. Then, availability loss at the absorber is increased with increasing exergy input at the absorber. The result of higher exergy loss can be reduced by increasing the surface area of the absorber, consequently, increasing the cost of the absorber. Meanwhile, availability loss at the absorber is increased, exergy of heat flux at the absorber, which equals the work 
obtained by a Carnot engine operating between $T_{a b}$ and $T_{o}$, increases due to increasing heat rejected at the absorber. This exergy increased causes the exergy efficiency based on the second law to increase with the value of $44.66 \%$ from the value of $33.17 \%$ for a conventional cycle when the two cycles is considered at the same energy input introduced to the system. As is shown in Table 4, the next largest exergy loss is occurred in the generator due to the temperature difference between the heat source and the temperature of the working fluid.

TABLE - 4 Exergy loss for the cycle

\begin{tabular}{|l|c|}
\hline \multicolumn{1}{|c|}{ Components } & Exergy loss $\Delta \psi,(\mathrm{kW})$ \\
\hline Conventional cycle: & 73.50255 \\
Generator & -24.25520 \\
Condenser & -163.3386 \\
Evaporator & 102.1110 \\
Absorber & -0.049438 \\
Solution pump & 0.053294 \\
Solution expansion valve & 0.12850 \\
Solution heat exchanger & -0.006864 \\
Refrigerant pump & -11.8547 \\
Total exergy loss & \\
\hline Modified cycle: & 164.3006 \\
\hline Absorber & 50.33486 \\
Total exergy loss & \\
\hline
\end{tabular}

\section{Conclusion}

A theoretical comparative study of thermodynamic between a lithium-bromide ejection AHT cycle and a conventional cycle is investigated and presented in this paper. For the first law thermodynamic reflects the quantity of energy, the conventional AHT cycle obtain higher first law performance (COP) due to combining an ejector developed to be the modified cycle. Moreover, second law analysis provides an alternate view of cycle performance and provides an insight that the first law method cannot. It is proved to be a simple and effective tool, by providing information to identify the less efficient components of the system and how losses at different devices are interdependent and where a given design should be modified for the best performance. For the second law analysis, the total exergy loss and exergy loss of each component are calculated. For the comparison of two cycles, exergy loss at any components is determined in the same pattern. The only different analysis is the absorber with and without combining an ejector. Results show that the absorber has the highest exergy loss. In the comparison of two cycles based on the same energy input introduced to the cycle, a modified cycle has higher exergy loss at the absorber than a conventional one due to higher temperature difference between the absorber and surroundings.

\section{Acknowledgments}

The authors would like to thank National Energy Policy Office (NEPO) and School of Renewable Energy Technology at Naresuan University in Thailand for their support in this research.

\section{References}

[1] Aphornratana. S and Eames. IW, "Thermodynamic analysis of absorption refrigeration cycles using the second law of thermodynamic method", International journal of refrigeration, Vol. 18, No. 4, pp 244-252, 1995.

[2] ASHRAE handbook 2001 fundamentals. Atlanta: American Society of Heating, Refrigerating and AirConditioning Engineers, Inc.

[3] Chen. LT, "A new ejector-absorber cycle to improve the COP of an absorption refrigeration system", Applied Energy, Vol. 30, pp 37-51, 1988.

[4] Lee. SF and Sherif. SA, "Second law analysis of multistage lithium bromide water absorption heat transformers", ASHRAE Transactions, Part 1, pp 105116, 2000.

[5] Lee. RJ, Diguilio. RM, Jeter. SM and Teja. AS, "Properties of lithium bromide-water solutions at high temperatures and concentrations II: Density and Viscosity", ASHRAE Transactions, Vol. 96(1), pp 709714, 1990.

[6] McNeely. LA, "Thermodynamic properties of aqueous solution of lithium bromide", ASHRAE transactions, Vol. 85, Part I, pp 413-434, 1979.

[7] Patterson. MR and Perez-Blanco. H, "Numerical fits of the properties of lithium bromide water solutions," ASHRAE Transactions, pp 2059-2077, 1988.

[8] Pongtornkulpanich. A, Thepa. S and Amornkitbamrung. M, “Analysis of ejector dimensions on performance evaluation of ejector-absorber cycle with using $\mathrm{LiBr} / \mathrm{H}_{2} \mathrm{O}$ as a working fluid", Proceedings of the international conference on village power from renewable energy in Asia, Vol. 1, pp 219-224, Thailand.

[9] Shi. L, Yin. J, Wang. S and Zhu. MS, "Study on a new ejection-absorption heat transformer", Applied Energy, Vol. 68, pp 161-171, 2001.

[10] Talbi. MM and Agnew. B, "Exergy Analysis: an absorption refrigerator using lithium bromide and water as the working fluids", Applied thermal Engineering, Vol. 20, pp 619-630, 2000.

[11] Yin. Juan, Shi. Lin, Zhu. Ming-Shan and Han. LiZhong, "Performance analysis of an absorption heat transformer with different working fluid combinations", Applied Energy, Vol. 67, pp 281-292, 2000. 